\title{
Streptococcal Receptor Polysaccharides: Recognition Molecules for Oral Biofilm Formation
}

\author{
Yasuo Yoshida, Robert J Palmer, Jinghua Yang, Paul E Kolenbrander and \\ John O Cisar*
}

Address: Oral Infection and Immunity Branch, National Institute of Dental and Craniofacial Research, National Institutes of Health, Bethesda, MD 20892-4352, USA

Email: Yasuo Yoshida - yasuoy@iwate-med.ac.jp; Robert J Palmer - rjpalmer@dir.nidcr.nih.gov; Jinghua Yang - jy117h@nih.gov; Paul E Kolenbrander - pkolenbrander@dir.nidcr.nih.gov; John O Cisar* - jcisar@dir.nidcr.nih.gov

* Corresponding author

from Biotechnology and Biomaterials to Reduce the Caries Epidemic Seattle, USA. 13-15 June 2005

Published: 10 July 2006

BMC Oral Health 2006, 6(Suppl I):SI2 doi:I0.II86/I472-683I-6-SI-SI2

(c) 2006 Yoshida et al; licensee BioMed Central Ltd.

This is an open access article distributed under the terms of the Creative Commons Attribution License (http://creativecommons.org/licenses/by/2.0), which permits unrestricted use, distribution, and reproduction in any medium, provided the original work is properly cited.

\begin{abstract}
Background: Strains of viridans group streptococci that initiate colonization of the human tooth surface typically coaggregate with each other and with Actinomyces naeslundii, another member of the developing biofilm community. These interactions generally involve adhesin-mediated recognition of streptococcal receptor polysaccharides (RPS). The objective of our studies is to understand the role of these polysaccharides in oral biofilm development.
\end{abstract}

Methods: Different structural types of RPS have been characterized by their reactions with specific antibodies and lectin-like adhesins. Streptococcal gene clusters for RPS biosynthesis were identified, sequenced, characterized and compared. RPS-producing bacteria were detected in biofilm samples using specific antibodies and gene probes.

Results: Six different types of RPS have been identified from representative viridans group streptococci that coaggregate with $A$. naeslundii. Each type is composed of a different hexa- or heptasaccharide repeating unit, the structures of which contain host-like motifs, either GaINAc $\beta$ I$3 \mathrm{Gal}$ or Gal $\beta$ I-3GalNAc. These motifs account for RPS-mediated recognition, whereas other features of these polysaccharides are more closely associated with RPS antigenicity. The RPSdependent interaction of $S$. oralis with $A$. naeslundii promotes growth of these bacteria and biofilm formation in flowing saliva. Type specific differences in RPS production have been noted among the resident streptococcal floras of different individuals, raising the possibility of RPS-based differences in the composition of oral biofilm communities.

Conclusion: The structural, functional and molecular properties of streptococcal RPS support a recognition role of these cell surface molecules in oral biofilm formation. 


\section{Background}

Colonization of the human tooth surface is initiated by a limited number of gram-positive species, primarily viridans group streptococci [1]. These bacteria attach to host salivary components that coat the mineral surface and, through growth and interactions between species, form a relatively simple biofilm community (i.e. early plaque). Members of this community can activate host cells, and the biofilm itself creates a habitat for additional species, some of which are closely associated with the initiation and progression of dental caries and periodontal disease [2]. In the current communication we summarize evidence for the hypothesis that the surface polysaccharides of certain viridans group streptococci are receptors for lectin-like adhesins present on other members of the developing oral biofilm community. Studies of how these components influence biofilm development may provide insights into the etiology and pathogenesis of biofilmrelated oral diseases.

\section{Early Biofilm Formation Involves a Limited Number of Microbial Species}

An attractive experimental model for defining early events in oral biofilm formation involves the incubation of retrievable enamel chips in the human oral cavity for periods of time from 4 to 12 hrs. Scanning electron micrographs of chips removed during this period suggest that colonization is initiated by the attachment of individual microorganisms to the saliva-coated mineral surface and proceeds primarily by the growth of attached bacteria as spreading microcolonies [3]. These microcolonies typically consist of a peripheral monolayer of dividing cocci and rods and a central region containing multiple bacterial layers. S. sanguinis, $S$. oralis and S. mitis were the most prominent species identified in parallel microbiological studies [2] and together comprised approximately $80 \%$ of the total cultivatable flora. Gram-positive pleomophic rods, mostly strains of Actinomyces naeslundii, made up another 5 to $10 \%$ of the total. Thus, primary colonization of the saliva-coated mineral surface involves the formation of a relatively simple biofilm community.

Interestingly, S. mutans, the principal agent of human dental caries, was generally not identified from early biofilms formed on enamel chips following incubation in the oral cavities of individuals with active caries [4]. Moreover, when this species was detected, it accounted for less than $2 \%$ of the total early streptococcal flora. Differences in the relative proportions of other streptococcal species were however noted between the early flora of caries active and caries free individuals. Specifically, the proportion of $S$. mitis was generally elevated at the expense of $S$. sanguinis in caries active individuals. The ecological consequences of this population shift are not well understood. However, they may include a lowering of the early plaque
$\mathrm{pH}$ as suggested from comparative studies of acid production by representative strains of these streptococcal species [5]. A more acidic environment could in turn favor the succession of aciduric species such as $S$. mutans, resulting in rapid caries development. Thus, the etiology and pathogenesis of oral disease may well be linked to ecological properties of the early biofilm community.

\section{Structural Basis of Receptor Polysaccharide (RPS)- Mediated Interbacterial Adhesion}

Bacterial properties that contribute to development of the early biofilm community may include the surface adhesins and receptors that mediate the coaggregations observed between different strains of $S$. sanguinis, S. gordonii, S. oralis, S. mitis and A. naeslundii [6]. The coaggregations between $A$. naeslundii and different streptococci are typically inhibited by GalNAc or Gal and result from lectin-like binding of A. naeslundii type 2 fimbriae to complementary receptors present on the streptococcal surface. These receptors occur on most strains of $S$. oralis and on certain strains of S. sanguinis, S. gordonii and S. mitis. Many but not all streptococci that possess such receptors also participate in coaggregations with other strains of $S$. sanguinis or S. gordonii. These coaggregations are inhibited by GalNAc and result from lectin-like binding of surface adhesins present on the strains of S. sanguinis or S. gordonii [7]. Thus, an extensive network of adhesive interactions occurs among different members of the early biofilm community.

The structural basis of the coaggregations observed between different bacteria is evident from the carbohydrate-binding specificities of the surface adhesins present on strains of A. naeslundii, S. sanguinis and S. gordonii, and from the structures of the complementary receptors present on other streptococcal strains. The type 2 fimbriae of $A$. naeslundii, in addition to mediating coaggregations with streptococci, mediate the adhesion of A. naeslundii to surface-associated host glycoconjugates $[8,9]$. Two different receptor structures have been identified, terminal GalNAc $\beta 1-3 \mathrm{Gal}$ of globoside and terminal Gal $\beta 1$ 3GalNAc of asialo-O-linked glycoproteins and gangliosides. Consistent with these findings, soluble GalNAc $\beta 1$ 3Gal- and Gal $31-3 \mathrm{GalNAc}$-containing ligands are potent inhibitors of $A$. naeslundii type 2 fimbriae-mediated adhesion [10]. These disaccharides differ only in the position of the $\mathrm{N}$-acetyl group. Consequently, the ability of each to inhibit binding of $A$. naeslundii type 2 fimbriae presumably depends on common features of these structures. The GalNAc-binding surface adhesins of $S$. sanguinisSK1 and $S$. gordonii DL1 also recognize terminal GalNAc $\beta 1-3 \mathrm{Gal}$ [11]. However, these adhesins do not bind terminal Gal $\beta 1$-3GalNAc of immobilized glycocongugates. In accordance with these findings, the coaggregations observed between strains of S. sanguinis or S. gordonii and 


\title{
$1 \mathrm{Gn}\left[-6 \mathrm{Galf} \beta 1-6 \mathrm{GaINAc} \beta 1-3 \mathrm{Gal} \alpha 1-\mathrm{PO}_{4}^{-}-6 \mathrm{GalNAc} \alpha 1-3 \mathrm{Rha} \beta 1-4 \mathrm{Glc} \beta 1-\right]_{n}$
}

\author{
$2 \mathrm{Gn}\left[-6 \mathrm{Galf} \beta 1-6 \mathrm{GaINAc} \beta 1-3 \mathrm{Gal} \alpha 1-\mathrm{PO}_{4}^{-}-6 \mathrm{GalNAc} \alpha 1-3 \mathrm{Rha} \beta 1-4 \mathrm{Glc} \beta 1-\right]_{n}$ \\ Rhaor ${ }^{2}$
}

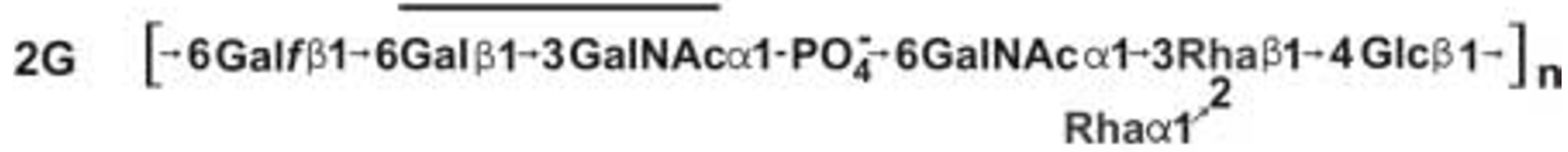

3G

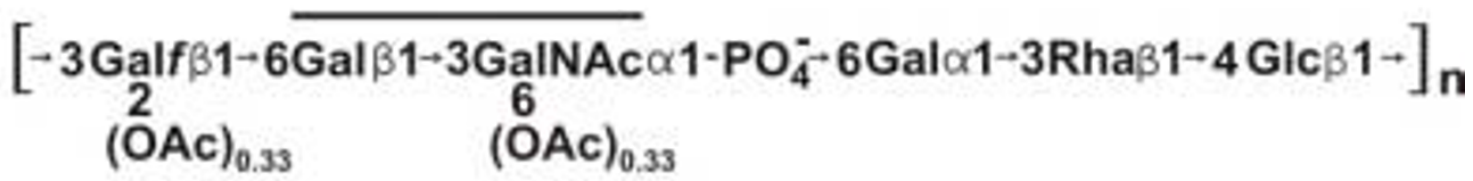

$4 \mathrm{Gn} \quad\left[-6 \mathrm{Gal} \beta \beta 1-6 \mathrm{GalNAc} \beta 1-3 \mathrm{Gal} \alpha 1-1 \text { ribitol5-PO }{ }_{4}^{-}-6 \mathrm{Galf} \beta 1-3 \mathrm{Gal} \beta 1-\right]_{n}$

$5 \mathrm{Gn} \quad\left[-6 \mathrm{Gal} f \beta 1-6 \mathrm{GalNAc} \beta 1-3 \mathrm{Gal} \alpha 1-3 \text { ribitol5-PO } \mathrm{O}_{4}^{-}-6 \mathrm{Gal} \beta \beta 1-3 \mathrm{Gal} \beta 1-\right]_{n}$

Figure I

The six structural types of RPS identified from strains of S. sanguinis, S. gordonii, S. oralis and S. mitis that coaggregate with A. naeslundii. Partial O-acetylation of type 3G RPS is indicated. Lines indicate the location of GalNAc $\beta$ I-3Gal (Gn) or Gal $\beta$ I$3 \mathrm{GalNAc}(\mathrm{G})$ recognition motifs within the hexa- or heptasaccharide repeating units of different RPS structural types.

other streptococci are inhibited more effectively by soluble GalNAc $\beta 1$-3Gal- than Gal $\beta 1-3$ GalNAc-containing ligands [6]. Thus, the $\mathrm{N}$-acetyl group of GalNAc $\beta 1-3 \mathrm{Gal}$ is critical for binding of the streptococcal adhesins that mediate these interactions.

Structural studies of over 20 representative strains of $S$. sanguinis, $S$. gordonii, $S$. oralis and $S$. mitis that participate in type 2 fimbriae-mediated coaggregations with A. naeslundii have resulted in the identification of six different streptococcal receptor polysaccharides (RPS), each composed of a distinct hexa- or heptasaccharide repeating unit (Fig. 1) [12]. Remarkably, a host-like receptor motif for binding of A. naeslundii type 2 fimbriae occurs within each RPS repeating unit. Four structural types of RPS contain GalNAc $\beta 1$-3Gal (Gn) motifs (i.e., RPS types $1 \mathrm{Gn}, 2 \mathrm{Gn}$,
$4 \mathrm{Gn}$ and $5 \mathrm{Gn}$ ) while the other two types contain Gal $\beta 1$ 3 GalNAc (G) motifs (i.e., RPS types 2G and 3G). All streptococci that bear these polysaccharides are coaggregation partners of $A$. naeslundii. However, only streptococci that bear Gn-types of RPS are coaggregation partners of $S$. sanguinisSK1 and S. gordonii DL1. The GalNAc binding adhesins of these strains do not recognize G-types of RPS. Thus, the occurrence of Gn and G types of RPS on different streptococci may influence biofilm development.

Other features of RPS that are conserved between structural types may contribute to adhesin binding of these linear polysaccharides. Such features include the flexibility of the $\beta 1-6$ linkage from Galf and the anionic phosphodiester bond that flank each recognition motif $[13,14]$. This region, although critical for interbacterial adhesion, con- 


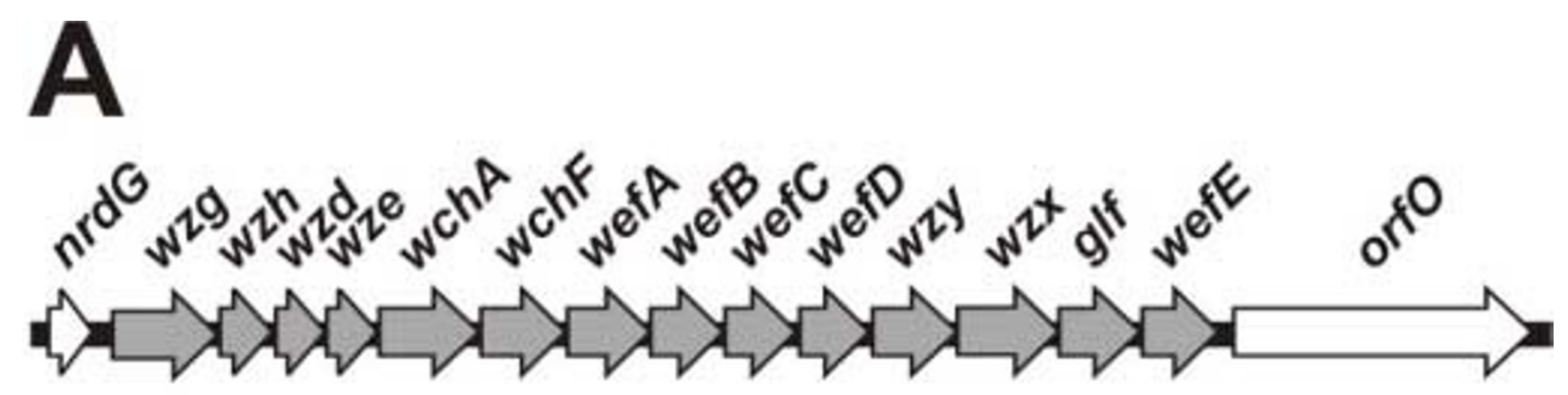

B

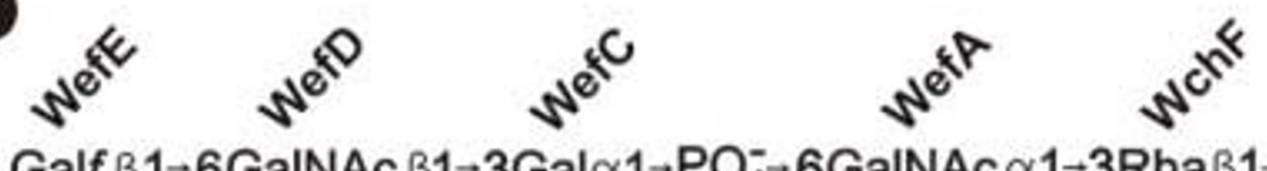

Galf $\beta 1-6$ GalNAc $\beta 1-3 \mathrm{Gal} \alpha 1-\mathrm{PO}_{4}^{-}-6 \mathrm{GalNAc} \alpha 1 \rightarrow 3 \mathrm{Rha} \beta 1-4 \mathrm{Glc}-\mathrm{PP}$-Lipid

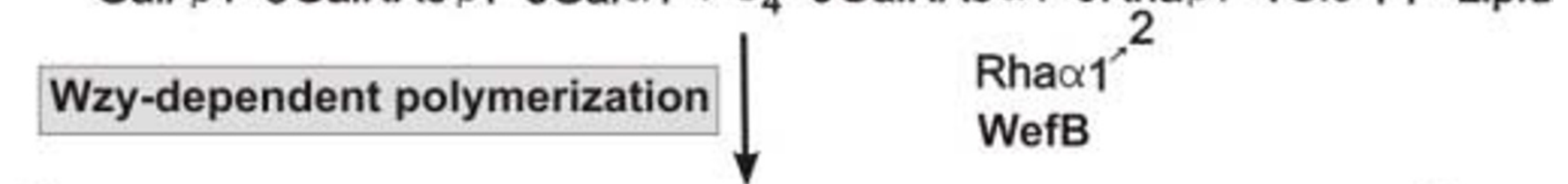

$\left[\begin{array}{c}-6 \text { Galf } \beta 1-6 \mathrm{GalNAc} \beta 1-3 \mathrm{Gal} \alpha 1 \rightarrow \mathrm{PO}_{4}^{-}-6 \mathrm{GalNAc} \alpha 1-3 \mathrm{Rha} \beta 1-4 \mathrm{Glc} \beta 1- \\ {\mathrm{Rha} \alpha 1^{\prime 2}}^{2}\end{array}\right] \mathbf{n}$

Figure 2

Molecular basis of type 2Gn RPS biosynthesis and structure. (A) The operon for type 2Gn RPS biosynthesis in S. gordonii 38 consists of 14 genes located between $\mathrm{nrdG}$ and orfO. The first four of these encode regulatory proteins. The remaining 10 genes include seven for putative glycosyltransferases, wzx and wzy for the transport and polymerization of RPS repeating units and glf for the epimerase that supplies UDP-Galf, one of five essential RPS precursors. (B) The deduced roles of the seven glycosylytransferases encoded by the type 2Gn RPS gene cluster in synthesis of the corresponding lipid-linked heptasaccharide repeating unit. The $\beta I-6$ linkage between Glc and Galf in type 2Gn RPS is formed by Wzy-dependent polymerization of RPS repeating units.

tributes little to the antigenicity of different RPS structural types. Instead, other structural features such as the Rha branch present in types 2Gn and 2G RPS [15] form the major epitopes of anti-RPS antibodies. Consequently, the reactions of types $2 \mathrm{Gn}$ and $2 \mathrm{G}$ RPS are similar as antigens but distinct as receptors. Other structural types such as types $1 \mathrm{Gn}$ and $2 \mathrm{Gn}$ RPS react as similar receptors but different antigens. Such findings raise the possibility that the production of different antigenic types of RPS contributes to evasion of the host secretory immune response during oral biofilm formation. However, the presence of specific anti-RPS antibodies has not been detected in samples of whole human saliva. Thus, further studies of the host response (or the lack of a response) to these molecules are needed.

\section{Molecular Basis of RPS Structure and Function}

Results from recent molecular studies have identified biosynthetic gene clusters for each of the six RPS structural types. As illustrated for the type $2 \mathrm{Gn}$ RPS gene cluster of $S$. gordonii 38 (Fig. 2) [16], the 5'-ends of each RPS cluster contain four common regulatory genes (i.e., wzg, wzh, wzd and wze). Homologues of these genes occur widely in polysaccharide gene clusters of gram-positive bacteria, including capsular polysaccharide genes clusters of $S$. pneumoniae [17]. The regulatory region of each RPS gene 


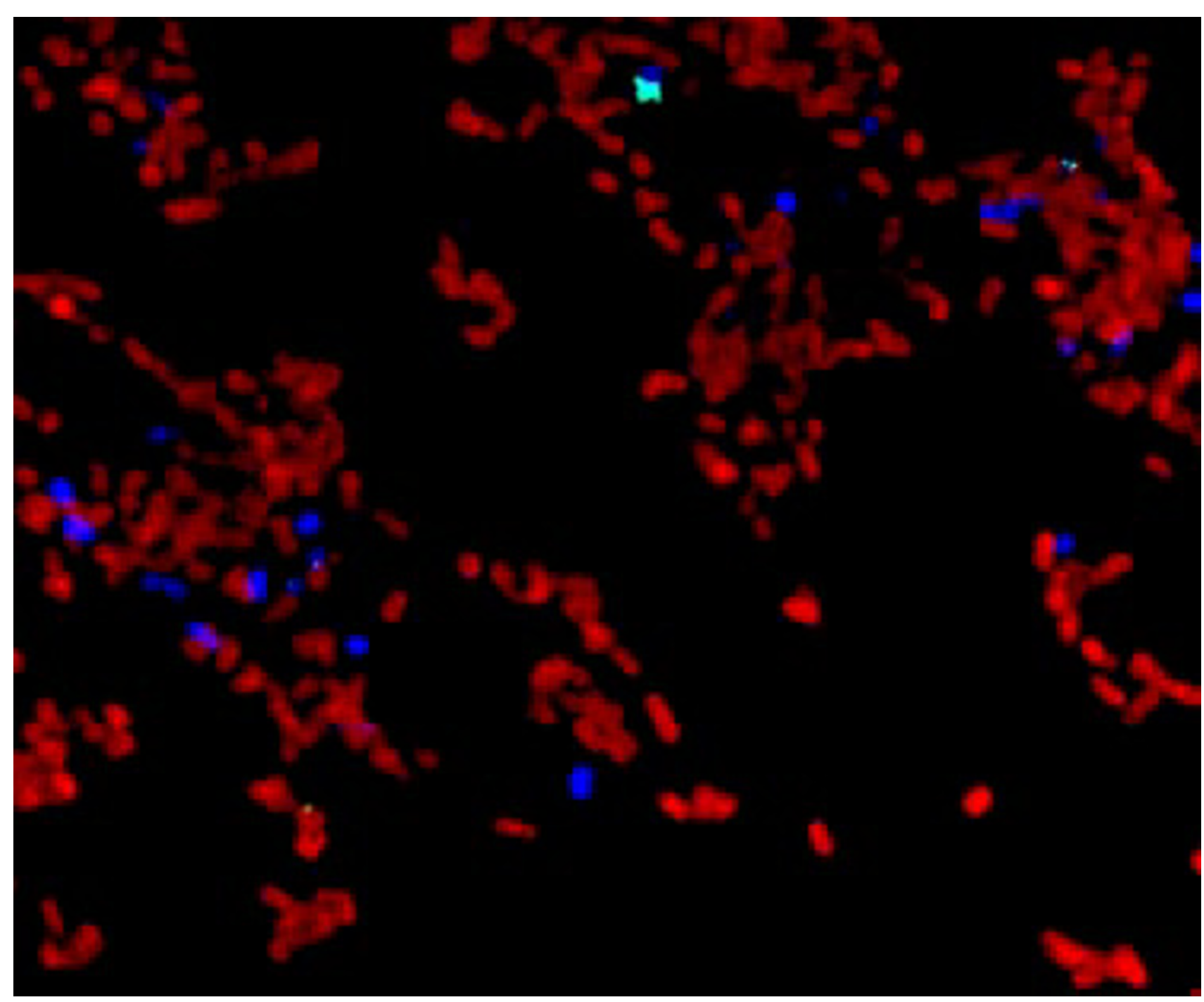

\section{Figure 3}

Laser confocal micrograph of an early biofilm formed on the surface of an enamel chip incubated 4 hr in vivo showing the presence of immono-labeled A. naeslundii (blue) within the monolayer of immuno-labeled RPS-producing streptococci (red).

cluster is followed by genes for the glycosyltransferases that synthesize the lipid-linked, type-specific RPS repeating unit. High homology exists between a number of genes for glycoslytransferases in strains of $S$. gordonii and $S$. oralis [18], suggesting horizontal gene transfer between these species. Moreover, the presence or absence of specific genes is closely correlated with structural differences that exist between different types of RPS. For example, the Rha branch that distinguishes type $2 \mathrm{Gn}$ from $1 \mathrm{Gn}$ RPS depends on the glycosyltransferase encoded by wefB, a gene that is present in the type $2 \mathrm{Gn}$ RPS cluster of $S$. gordonii 38 but not in the type $1 \mathrm{Gn}$ RPS gene cluster of $S$. ora- lis 34 [18]. Likewise, different pairs of adjacent genes, wefC and wefD in the type $2 \mathrm{Gn}$ cluster of $S$. gordonii 38 and wefF and wefG in the type $2 \mathrm{G}$ cluster of $S$. oralis J22, account for the distinct recognition motifs present in the corresponding polysaccharides of these strains [19]. Additional genes in each RPS cluster encode a putative flipase (Wzx), which transports the oligosaccharide moiety of the lipid-linked repeating unit to the outer surface of the cytoplasmic membrane and a putative polymerase (Wzy), which links repeating units end-to-end forming the linear polysaccharide chain. Polymerization involves the formation of a glycosidic linkage between the first and last sugars of each 

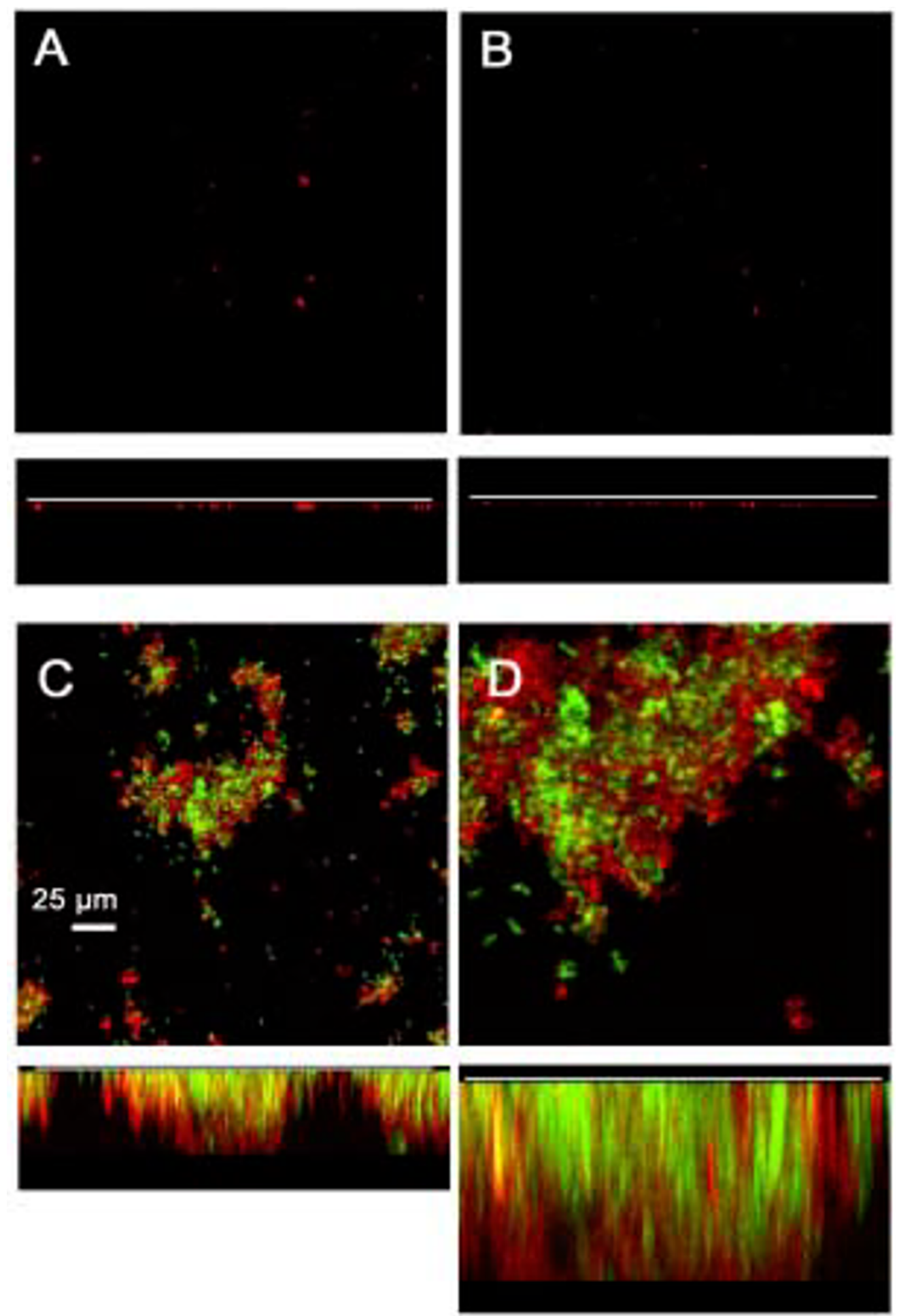

\section{Figure 4}

RPS-mediated interbacterial adhesion promotes the growth of S. oralis 34 and A. naeslundii $\mathrm{TI} 4 \mathrm{~V}$ as a biofilm in flowing human saliva. Flow cells were incubated overnight at $37 \mathrm{C}$ following inoculation with different combinations of wild type strain 34 or an RPS-negative mutant and wild type strain TI4V or a type 2 fimbriae deficient mutant. Biofilms were labeled with conjugated antibodies to detect streptococci (red) and actinomyces (blue) and examined confocal fluorescent microscopy. 
RPS repeat (i.e., Glc $\beta 1-6 \mathrm{Gal} f$ in types $1 \mathrm{Gn}, 2 \mathrm{Gn}$ and $2 \mathrm{G}$ RPS, Glc $\beta 1-3 \mathrm{Gal} f$ in type $3 \mathrm{G}$ RPS and Gal $\beta 1-6 \mathrm{Gal} f$ in types $4 \mathrm{Gn}$ and 5Gn RPS).

Additional genes control the synthesis of nucleotidelinked sugars that are essential precursors for RPS biosynthesis. One of these $(\mathrm{glf})$ encodes galactofuranose mutase, the enzyme that catalyzes the conversion of UDP-Galactopyranose to UDP-Galactofuranose. This gene invariably occurs within the RPS gene clusters of different strains. The location of other genes for nucleotide sugar biosynthesis varies between streptococcal species. For example, in S. gordonii 38, the first three genes of the dTDP-L-Rhamnose biosynthetic pathway (i.e., rmlA, rmlC and $r m l B$ ) occur in a separate operon with galE2, the gene for a bifunctional galactose epimerase that supplies both UDPGal and UDP-GalNAc for polysaccharide biosynthesis [16]. The final gene for dTDP-L-Rhamnose biosynthesis (i.e., rmlD) is transcribed independently, downstream of the rml-galE2 operon. In contrast, $r m l A, r m l C$ and $r m l B$ of $S$. oralis strains 34 and $\mathrm{J} 22$ occur at the 3 '-end of the respective type $1 \mathrm{Gn}$ and $2 \mathrm{G}$ RPS gene clusters of these strains, while rmlD occurs immediately downstream but transcribed in the opposite direction $[19,18]$. The differences that exist between the RPS gene clusters of $S$. gordonii and $S$. oralis, both in terms of their organization and nucleotide sequence homologies, raise the interesting possibility that the evolution of RPS production in these bacteria occurred following the divergence of these species. The four RPS-producing species of oral streptococci, S. sanguinis, S. gordonii, S. oralis and S. mitis, are closely related members of the mitis group [20]. Members of this group, which includes $S$. pneumoniae, are all intimately associated with the oral cavity and upper respiratory tract of man. Thus, the evolution of certain species as members of the human oral biofilm community may be closely linked with the evolution of RPS production. The identification of genes for RPS structure and function provides a beginning basis for further phylogenetic studies to examine this intriguing possibility.

\section{Role of RPS-mediated Interbacterial Adhesion in Biofilm Development}

Laser confocal microscopy performed in conjunction with different specific antibodies has been used to examine the distribution of RPS-bearing streptococci and type 2 fimbriated A. naeslundii in early biofilms formed in vivo on retrievable enamel chips [21]. Bacteria labeled for cell surface RPS were seen in large numbers on chips following 8 hr incubation in vivo. Other bacteria labeled with antibodies specific for strains of $A$. naeslundii were also present, but in much lower numbers. Significantly, the latter cells (i.e., type 2 fimbriated A. naeslundii) were found almost exclusively within microcolonies of RPS-producing bacteria, thereby supporting the role of RPS-mediated interbacterial adhesion in early biofilm formation. Moreover, A. naeslundii has been identified within spreading monolayers of RPS-producing streptococci formed during early in vivo colonization of the enamel surface (Fig. 3).

The ecological role of RPS-mediated interbacterial adhesion may be to promote the formation of food chains and other mutualistic interactions that require close contact between different bacteria. Evidence for this possibility has been obtained using a flowcell model of biofilm formation in which human saliva is the sole source of nutrients for bacterial growth [22]. Biofilm formation was limited or did not occur under these conditions when either RPS-producing $S$. oralis 34 or type 2 fimbriated $A$. naeslundii $\mathrm{T} 14 \mathrm{~V}$ were introduced separately into flowcells. However, a luxuriant mixed-species biofilm formed when these two strains were introduced together. These observations have recently been extended by the results of similar experiments performed with these wild-type strains and corresponding mutant strains that specifically lack cellsurface RPS or type 2 fimbriae. As expected, wild-type $S$. oralis 34 and $A$. naeslundii T14V formed a luxuriant biofilm (Fig. 4). However, biofilm formation was greatly reduced when either wild-type strain was paired with the non-adherent mutant of the other cell type (i.e., RPS-negative $S$. oralis 34 or type 2 fimbriae-negative $A$. naeslundii $\mathrm{T} 14 \mathrm{~V})$. Thus, RPS-mediated interbacterial adhesion appears to promote the establishment of a mutualistic association between $S$. oralis and $A$. naeslundii that is essential for luxuriant growth and mixed-species biofilm formation in flowing human saliva.

\section{Characterization of RPS-Producing Bacteria from Different Individuals}

The identification of six structural types of RPS is based on the characterization of representative strains of the four RPS-producing species. Consequently, it is unclear how many different RPS-producing strains occur within the streptococcal flora of any one individual. To address this question, we have begun to characterize these bacteria from individual volunteers. This involves the identification of RPS-producing clones from samples of $8 \mathrm{hr}$ biofilms by colony immunoblotting with a cocktail of RPSspecific antibodies and the subsequent characterization of individual clones by the reactions with specific antibodies and adhesins. Initial results of these studies indicate the production of one predominant type of RPS by the resident streptococcal flora of each individual examined to date. Thus, 22 RPS-producing isolates from one volunteer all produced type $1 \mathrm{Gn}$ RPS while 19 RPS-producing isolates from another individual all produced type 2Gn RPS. In addition, 21 RPS-producing isolates from a third individual included 19 that produced type 2Gn RPS and two that produced type $1 \mathrm{Gn}$ RPS. PCR-based genotyping [23] of these isolates suggests the presence of from one to three 
different RPS-producing clones per individual. These clones appear to be $S$. oralis or $S$. gordonii based on sequencing of a housekeeping gene [24]. Whether RPSproducing clones of different individuals are subject to replacement or to chromosomal rearrangement over time as has been described for strains of S. mitis [25] and S. oralis [26] remains to be determined.

\section{Conclusion}

Over $90 \%$ of the RPS-producing streptococci identified from samples of early supragingival plaque from each of five individuals are type $1 \mathrm{Gn}$ or $2 \mathrm{Gn}$ RPS producing clones. The preponderance of these bacteria in the plaque samples examined to date raises a number of intriguing possibilities concerning the occurrence and distribution of the streptococci that produce other structural types. Clearly, one possibility is that the streptococcal floras of certain individuals will be found to produce type $2 \mathrm{G}, 3 \mathrm{G}$, $4 \mathrm{Gn}$ or $5 \mathrm{Gn}$ RPS, thereby indicating significant differences in RPS production between individuals. Alternatively, the RPS-producing flora of each individual, including those that have been examined, may be more complex than is presently recognized. If so, streptococci that produce structural types other than type $1 \mathrm{Gn}$ or $2 \mathrm{Gn}$ RPS may emerge as the early biofilm community matures or perhaps appear during the colonization of other oral sites. In any case, it will be important to determine whether RPS-producing streptococci, especially those that produce Gn- and G-types, exist within distinct biofilm communities. The existence of RPS-based differences in the composition of biofilm communities would firmly establish the recognition role of these polysaccharides in biofilm development and could provide important new insights into the etiology and pathogenesis of biofilm-related oral diseases, including dental caries.

Another intriguing area of investigation involves the natural history of RPS-producing streptococci in the human host. Available findings indicate that these bacteria are transmitted from adults to infants shortly after tooth eruption. It is unclear, however, whether the resident RPS-producing streptococcal flora, once acquired, is stable, or whether changes in the population of RPS-producing clones occur over the lifetime of each individual. New structural types of RPS may evolve gradually and be disseminated by transmission between individuals. Alternatively, new types may arise frequently by the horizontal transfer of genes for RPS biosynthesis between different streptococcal strains and species within the resident flora of each individual. Current molecular studies of RPS production are directed toward distinguishing these possibilities.

\section{Competing interests}

The authors declare that they have no competing interests.

\section{Authors' contributions}

All authors read and approved the final manuscript.

\section{Acknowledgements}

This work was supported by the Intramural Research Program of the NIH, NIDCR.

\section{References}

I. Nyvad B, Kilian M: Microbiology of the early colonization of human enamel and root surfaces in vivo. Scand J Dent Res 1987, 95(5):369-380.

2. Gibbons RJ: Bacterial adhesion to oral tissues: a model for infectious diseases. J Dent Res 1989, 68(5):750-760.

3. Nyvad B, Fejerskov O: Scanning electron microscopy of early microbial colonization of human enamel and root surfaces in vivo. Scand J Dent Res 1987, 95(4):287-296.

4. Nyvad B, Kilian M: Comparison of the initial streptococcal microflora on dental enamel in caries-active and in cariesinactive individuals. Caries Res 1990, 24(4):267-272.

5. de Soet JJ, Nyvad B, Kilian M: Strain-related acid production by oral streptococci. Caries Res 2000, 34(6):486-490.

6. Hsu SD, Cisar JO, Sandberg AL, Kilian M: Adhesive properties of viridans group streptococcal species. Microb Ecol Health Dis 1994:125-137.

7. Kolenbrander PE, Andersen RN, Moore LV: Intrageneric coaggregation among strains of human oral bacteria: potential role in primary colonization of the tooth surface. Appl Environ Microbiol 1990, 56( I 2):3890-3894.

8. Brennan MJ, Joralmon RA, Cisar JO, Sandberg AL: Binding of Actinomyces naeslundii to glycosphingolipids. Infect Immun 1987, 55(2):487-489.

9. Ruhl S, Sandberg AL, Cole MF, Cisar JO: Recognition of immunoglobulin AI by oral actinomyces and streptococcal lectins. Infect Immun 1996, 64(I 2):542I-5424.

10. Cisar JO, Sandberg AL, Abeygunawardana C, Reddy GP, Bush CA: Lectin recognition of host-like saccharide motifs in streptococcal cell wall polysaccharides. Glycobiology 1995, 5(7):655-662.

II. Takahashi Y, Ruhl S, Yoon JW, Sandberg AL, Cisar JO: Adhesion of viridans group streptococci to sialic acid-, galactose- and $\mathbf{N}$ acetylgalactosamine-containing receptors. Oral Microbiol Immunol 2002, I7(4):257-262

12. Cisar JO, Sandberg AL, Reddy GP, Abeygunawardana C, Bush CA: Structural and antigenic types of cell wall polysaccharides from viridans group streptococci with receptors for oral actinomyces and streptococcal lectins. Infect Immun 1997, 65(I 2):5035-504I.

13. Mclntire FC, Crosby LK, Vatter AE, Cisar JO, McNeil MR, Bush CA, Tjoa SS, Fennessey PV: A polysaccharide from Streptococcus sanguis 34 that inhibits coaggregation of $S$. sanguis 34 with Actinomyces viscosus TI4V. J Bacteriol 1988, I 70(5):2229-2235.

14. Xu Q, Bush CA: Molecular modeling of the flexible cell wall polysaccharide of Streptococcus mitis J22 on the basis of heteronuclear NMR coupling constants. Biochemistry 1996, 35(46): | 452|-| 4529.

15. Reddy GP, Abeygunawardana C, Bush CA, Cisar JO: The cell wall polysaccharide of Streptococcus gordonii 38: structure and immunochemical comparison with the receptor polysaccharides of Streptococcus oralis $\mathbf{3 4}$ and Streptococcus mitis J22. Glycobiology 1994, 4(2): 183-192.

16. Xu DQ, Thompson J, Cisar JO: Genetic loci for coaggregation receptor polysaccharide biosynthesis in Streptococcus gordonii 38. J Bacteriol 2003, I85(18):5419-5430.

17. Jiang SM, Wang L, Reeves PR: Molecular characterization of Streptococcus pneumoniae type 4, 6B, 8, and 18C capsular polysaccharide gene clusters. Infect Immun 200I, 69(3): 1244-1255.

18. Yoshida Y, Ganguly S, Bush CA, Cisar JO: Molecular basis of Lrhamnise branch formation in streptococcal coaggregation receptor polysaccharides. J Bacteriol 2006, I88(I I):4I25-4I30.

19. Yoshida Y, Ganguly S, Bush CA, Cisar JO: Carbohydrate engineering of the recognition motifs in streptococcal co-aggregation receptor polysaccharides. Mol Microbiol 2005, 58(I):244-56.

20. Kawamura $Y$, Hou XG, Sultana F, Miura H, Ezaki T: Determination of I6S rRNA sequences of Streptococcus mitis and Strepto- 
coccus gordonii and phylogenetic relationships among members of the genus Streptococcus. Int J Syst Bacteriol 1995, 45(2):406-408.

21. Palmer RJ Jr, Gordon SM, Cisar JO, Kolenbrander PE: Coaggregation-mediated interactions of streptococci and actinomyces detected in initial human dental plaque. J Bacteriol 2003, I 85( I I):3400-3409.

22. Palmer RJ Jr, Kazmerzak K, Hansen MC, Kolenbrander PE: Mutualism versus independence: strategies of mixed-species oral biofilms in vitro using saliva as the sole nutrient source. Infect Immun 200I, 69(9):5794-5804.

23. Alam S, Brailsford SR, Whiley RA, Beighton D: PCR-Based methods for genotyping viridans group streptococci. J Clin Microbiol 1999, 37(9):2772-2776.

24. Kawamura Y, Whiley RA, Shu SE, Ezaki T, Hardie JM: Genetic approaches to the identification of the mitis group within the genus Streptococcus. Microbiology 1999, I45(Pt 9):2605-26I3.

25. Hohwy J, Reinholdt J, Kilian M: Population dynamics of Streptococcus mitis in its natural habitat. Infect Immun 200I, 69(10):6055-6063.

26. Alam S, Brailsford SR, Adams S, Allison C, Sheehy E, Zoitopoulos L, Kidd EA, Beighton D: Genotypic heterogeneity of Streptococcus oralis and distinct aciduric subpopulations in human dental plaque. Appl Environ Microbiol 2000, 66(8):3330-3336.

Publish with Bio Med Central and every scientist can read your work free of charge

"BioMed Central will be the most significant development for disseminating the results of biomedical research in our lifetime. "

Sir Paul Nurse, Cancer Research UK

Your research papers will be:

- available free of charge to the entire biomedical community

- peer reviewed and published immediately upon acceptance

- cited in PubMed and archived on PubMed Central

- yours - you keep the copyright

Submit your manuscript here:

http://www.biomedcentral.com/info/publishing_adv.asp 